\title{
ERRATUM
}

\section{Triazolinediones enable ultrafast and reversible click chemistry for the design of dynamic polymer systems}

Stijn Billiet, Kevin De Bruycker, Frank Driessen, Hannelore Goossens, Veronique Van Speybroec, Johan M. Winne and Filip E. Du Prez

Nature Chemistry 6, 815-821 (2014); published online 11 August 2014; corrected after print 11 August 2014.

Technical issues with our online publication processes resulted in this Article being published the day after that referred to in the print version. The official date of publication is 11 August 2014.

\section{ERRATUM}

\section{High-performance $\mathrm{Ag}$-Co alloy catalysts for electrochemical oxygen reduction}

Adam Holewinski, Juan-Carlos Idrobo and Suljo Linic

Nature Chemistry 6, 828-834 (2014); published online 11 August 2014; corrected after print 11 August 2014.

Technical issues with our online publication processes resulted in this Article being published the day after that referred to in the print version. The official date of publication is 11 August 2014.

\section{CORRIGENDUM}

\section{Directed assembly of optoelectronically active alkyl- $\pi$-conjugated molecules by adding $n$-alkanes or $\pi$-conjugated species}

Martin J. Hollamby, Maciej Karny, Paul H. H. Bomans, Nico A. J. M. Sommerdijk, Akinori Saeki, Shu Seki,

Hiroyuki Minamikawa, Isabelle Grillo, Brian R. Pauw, Paul Brown, Julian Eastoe, Helmuth Möhwald and Takashi Nakanishi

Nature Chemistry 6, 690-696 (2014); published online 22 June 2014; corrected online 25 June 2014; corrected after print

3 September 2014.

In the version of this Article previously published, the fourth co-author's surname was spelt incorrectly, it should have read Sommerdijk. This has been corrected in the online versions of the Article. 